\title{
Interpersonal Conflict Among Nurses in Tertiary Hospitals in Dali, the People's Republic of China
}

\author{
Yongling Hua ${ }^{1}$, Mohammad Abbas Uddin ${ }^{2, ~ *, ~ A n o w a r u l ~ J a l a l ~ B h u i y a n ² ~}$ \\ ${ }^{1}$ Spinal Surgery Department, First Affiliated Hospital of Dali University, Dali, The People's Republic of China \\ ${ }^{2}$ College of Nursing, Dhaka, Bangladesh
}

\section{Email address:}

uabbas9@gmail.com (M. A. Uddin)

${ }^{*}$ Corresponding author

\section{To cite this article:}

Yongling Hua, Mohammad Abbas Uddin, Anowarul Jalal Bhuiyan. Interpersonal Conflict Among Nurses in Tertiary Hospitals in Dali, the People's Republic of China. Chemical and Biomolecular Engineering. Vol. 4, No. 1, 2019, pp. 10-13. doi: 10.11648/j.cbe.20190401.12

Received: March 28, 2019; Accepted: April 29, 2019; Published: May 23, 2019

\begin{abstract}
Interpersonal conflict is the interpersonal clashes, tension, animosity, and jealousy that occur between people. It is considered destructive as it is characterized by power struggles and personal issues and negatively affects group decisionmaking and task implementation. The aim of this study was to assess interpersonal conflict between nurses in tertiary hospitals in Dali, the People's Republic of China, and the relationship between interpersonal conflict and the nurses' various sociodemographic characteristics. The study found that, overall, nurses perceived a low level of interpersonal conflict. Nurses' age, marital status, education level, work time, appointment status, and work experience were non-significant variables, and job status a significant variable associated with interpersonal conflict score. This study provides baseline information about nurses' interpersonal conflict. Nurse managers should use this study's results to develop positive working environments and reduce interpersonal conflict among nurses.
\end{abstract}

Keywords: China, Interpersonal Conflict, Nurse

\section{Introduction}

Hospitals are often stressful environments featuring frequent change, challenging and difficult work, large numbers of staff, and a diversity of interactions As such, hospitals may also feature higher levels of conflict than other workplaces [1]. Conflict is experienced or perceived variations in common goals, values, attitudes, beliefs, feelings, or actions [2]. There are two forms: task conflict and interpersonal conflict [3]. Task conflict occurs when group members have different opinions about work tasks [4]. It is often considered to be constructive because it can lead to positive outcomes, such as better decision-making. Interpersonal conflict is interpersonal clashes, tension, animosity, and jealousy that occurs between group members. It is generally viewed as destructive. It is characterized by power struggles and personal issues, and it often undermines group decision-making and task implementation.

Nurses play different roles in hospitals, including care provision, education, and management. These different roles involve various types of interactions among nurses and other healthcare team members, significantly increasing the probability of interpersonal conflict occurring [1]. Indeed, interpersonal workplace conflict in hospitals is almost inevitable, and it can lead to lowered morale, decreased productivity and poor team performance [5]. It is also related to lower-quality patient care, more frequent medical errors, and higher direct and indirect care costs [6]. There are many causes of conflict, including poor communication, unclear expectations, conflicts of interest, competition over resources, performance deficiencies, staffing changes, and diversity in gender, culture, or age [7]. Although the negative effects of workplace interpersonal conflict are recognized, such conflict cannot be totally eliminated. Therefore, it is very important that group members learn skills and strategies for managing interpersonal conflict.

Studies conducted in different countries among nonnursing participants reported that participants perceived moderate [8-9], and low [10] level of interpersonal conflict. However, studies focusing on interpersonal conflict among nurses are scarce. Nursing involves a huge 
number of routine tasks, including observation, recording documents, administering medications, transfusion, nursing planning and evaluation, and monitoring vital signs. High workloads can undermine effective communication among nurses and may lead to interpersonal conflict. Therefore, it is useful to investigate interpersonal conflict among nurses. This study was conducted at two tertiary hospitals in Dali, a city in southern China. The hospitals provide inpatient, outpatient, and emergency health care. Typical nurse-topatient ratios are one nurse per 10-15 patients during a day shift and one nurse per 30-40 patients during a night shift [11]. This study's results will provide knowledge that allows nurse administrators to develop strategies to help their nurses by reducing and managing interpersonal conflict.

\section{Data and Methods}

A descriptive study design was used to examine the level of interpersonal conflict among nurses and to examine the relationship between their demographic characteristics and conflict scores. The target population was 1,156 nurses at two tertiary hospitals in Dali, Yunnan, China: Affiliated Hospital of Dali University (392 nurses) and Dali Bai Autonomous Prefecture People's Hospital (764 nurses). A sample size of 298 nurses was calculated using the Yamane formula [12]. The sample inclusion criteria were: 1) had worked as a nurse in the selected hospital for at least one year, and 2) involved in providing direct care to patients. The exclusion criterion was nurses had on vacation or maternal leave, or be studying, during the study.

Self-reported data were collected from the nurses between February 2018 and April 2018. Two instruments were used. The Demographic Data Form investigated age, gender, marital status, educational level, work unit, job status, work experience, work time, and appointment status. The Chinese Interpersonal Conflict Questionnaire, developed by the researcher, consisted of 20 items across four dimensions: interdependence (4 items), disagreement (4 items), interference ( 8 items), and negative emotion (4 items). All items were assessed on 11-point scales, ranging from 0 (not at all) to 10 (a lot). The total score range was between 0 and 200, with higher scores reflecting higher levels of interpersonal conflict. This questionnaire's content validity was confirmed by three experts and the reliability was confirmed (Cronbach's alpha coefficient $=.96)$.

Data from seven participants were incomplete and were discounted. Data from the remaining 291 participants were analyzed using a statistical program (SPSS 13.0). Descriptive statistics, including frequency, percentage, mean, and standard deviation, were used to analyze the nurses' demographic and interpersonal conflict data. The comparison between the two groups was carried out using one-way classification of analysis of variance (ANOVA).

\section{Results}

Table 1. Demographic Information of Nurses $(n=291)$.

\begin{tabular}{|c|c|c|}
\hline Demographic Information & Frequency (n) & Percentage (\%) \\
\hline \multicolumn{3}{|c|}{ Age (Mean 31.56, Range $=21-55$ years $)$} \\
\hline $20-30$ & 168 & 57.73 \\
\hline $31-40$ & 92 & 31.62 \\
\hline $41->50$ & 31 & 10.65 \\
\hline \multicolumn{3}{|l|}{ Gender } \\
\hline Female & 289 & 99.31 \\
\hline Male & 2 & 0.69 \\
\hline \multicolumn{3}{|l|}{ Marital status } \\
\hline Single & 61 & 20.96 \\
\hline Married & 225 & 77.32 \\
\hline Divorced & 5 & 1.72 \\
\hline \multicolumn{3}{|l|}{ Education level } \\
\hline Associate degree & 115 & 39.52 \\
\hline Diploma degree & 17 & 5.84 \\
\hline Bachelor degree & 159 & 54.64 \\
\hline \multicolumn{3}{|l|}{ Working unit } \\
\hline Medical & 96 & 32.99 \\
\hline Surgical & 86 & 29.55 \\
\hline Pediatric & 20 & 6.87 \\
\hline OB-GYN & 13 & 4.47 \\
\hline Operating room & 18 & 6.19 \\
\hline Emergency room & 19 & 6.53 \\
\hline ICU & 16 & 5.50 \\
\hline \multicolumn{3}{|l|}{ Job status } \\
\hline Junior nurse & 107 & 36.77 \\
\hline Senior nurse & 129 & 44.33 \\
\hline Nurse-in-Charge & 52 & 17.87 \\
\hline Associate chief nurse & 3 & 1.03 \\
\hline \multicolumn{3}{|l|}{ Working experience } \\
\hline$<5$ years & 55 & 18.90 \\
\hline $5-10$ & 141 & 48.45 \\
\hline $11-20$ & 62 & 21.31 \\
\hline $21->30$ & 33 & 11.34 \\
\hline \multicolumn{3}{|l|}{ Working shift } \\
\hline Day shift & 64 & 21.99 \\
\hline Rotating shift & 227 & 78.01 \\
\hline \multicolumn{3}{|l|}{ Employment status } \\
\hline Permanent nurses & 101 & 34.71 \\
\hline Temporary nurses & 190 & 65.29 \\
\hline
\end{tabular}

As per Table 1, most subjects were female, aged between 21 and 55. The average age was 31.56 years, and more than half of the subjects were between 20 and 30 years old. The majority of subjects were married (77.32\%). 54.64\% of subjects held a bachelor degree, with $39.52 \%$ holding an associate degree. $36.77 \%$ of subjects were junior nurses and $44.33 \%$ were senior nurses. Almost fifty per cent of the sample had between 5 and 10 years' experience. $32.99 \%$ worked in medical departments and $29.55 \%$ worked in surgical departments. The largest group of the subjects (78.01\%) worked on rotating shifts. $34.71 \%$ were permanently employed and $65.29 \%$ were temporary staff.

Table 2. Interpersonal Conflict of Nurses $(n=291)$.

\begin{tabular}{llll}
\hline Variable & Mean (M) & $\begin{array}{l}\text { Standard } \\
\text { Deviation (S.D.) }\end{array}$ & Level \\
\hline Interpersonal Conflict & 58.28 & 22.86 & Low \\
\hline
\end{tabular}

As per Table 2, overall, participants reported a low level of 
interpersonal conflict $(\mathrm{M}=52.51$, S.D. $=3.49)$.

Table 3. Categories of Interpersonal Conflict of Nurses $(n=291)$.

\begin{tabular}{llll}
\hline Variable & Frequency & Percentage & Level \\
\hline \multirow{3}{*}{ Interpersonal Conflict } & 211 & 72.5 & Low \\
& 79 & 27.1 & Moderate \\
& 1 & .3 & High \\
\hline
\end{tabular}

As per Table 3, the majority of participants (72.5\%) reported a low level of interpersonal conflict.

Table 4 shows that age, marital status, education level, work time, appointment status, and work experience were non-significant variables upon interpersonal conflict score. The only significant variable was job status $(\mathrm{f}=2.666, \mathrm{p}$ $=.048)$.

Table 4. Distribution of Subjects and Interpersonal Conflict Scores with Various-Demographic Variables $(n=291)$.

\begin{tabular}{|c|c|c|c|c|c|c|c|c|}
\hline Variables & Categories & $\begin{array}{l}\text { Number of } \\
\text { Participants (\%) }\end{array}$ & $\begin{array}{l}\text { Interpersonal Conflict } \\
(\text { Mean + S.D.) }\end{array}$ & $\begin{array}{l}\text { Sources of } \\
\text { variation } \\
\end{array}$ & df & $\begin{array}{l}\text { Mean } \\
\text { square }\end{array}$ & F-value & Sig \\
\hline \multirow{2}{*}{ Age } & 20- 40 years & $260(89.3)$ & $58.00+22.24$ & between & 1 & 187.99 & \multirow{2}{*}{.359} & \multirow[b]{2}{*}{.550} \\
\hline & More than 40 years & $31(10.7)$ & $60.61+27.84$ & within & 289 & 523.86 & & \\
\hline \multirow{2}{*}{ Marital Status } & Single & $61(20)$ & $56.69+22.00$ & between & 1 & 196.76 & \multirow{2}{*}{.376} & \multirow{2}{*}{.540} \\
\hline & Married & $230(79)$ & $58.71+23.11$ & Within & 289 & 523.83 & & \\
\hline \multirow{2}{*}{ Education } & Diploma and associate & $132(45.4)$ & $57.12+22.59$ & between & 1 & 327.33 & \multirow{2}{*}{.625} & \multirow{2}{*}{.430} \\
\hline & Bachelor and masters & $159(54.6)$ & $59.25+23.12$ & within & 289 & 523.38 & & \\
\hline \multirow{4}{*}{ Job status } & Junior nurse & $107(36.8)$ & $57.73+24.30$ & & & & \multirow{4}{*}{2.666} & \multirow{4}{*}{$.048^{*}$} \\
\hline & Senior nurse & $129(44.3)$ & $58.95+20.61$ & between & 3 & 1370.01 & & \\
\hline & Nurse in charge & $52(17.9)$ & $55.75+22.90$ & within & 287 & 513.84 & & \\
\hline & Associate chief nurse & $3(1.0)$ & $93.33+43.10$ & & & & & \\
\hline \multirow{2}{*}{ Working time } & Day shift & $64(22)$ & $59.67+24.22$ & between & 1 & 157.75 & \multirow{2}{*}{.301} & \multirow{2}{*}{.584} \\
\hline & Rotation & $227(78)$ & $57.89+22.50$ & within & 289 & 523.96 & & \\
\hline \multirow{4}{*}{$\begin{array}{l}\text { Appointment } \\
\text { status } \\
\text { Work } \\
\text { experience }\end{array}$} & Temporary & $190(65.3)$ & $57.72+24.30$ & between & 1 & 52.36 & \multirow{2}{*}{.100} & \multirow{2}{*}{.752} \\
\hline & Permanent & $101(34.7)$ & $58.60+22.04$ & within & 289 & 524.32 & & \\
\hline & 20 years & $258(88.7)$ & $58.21+22.21$ & between & 1 & 10.57 & & \\
\hline & More than 20 years & $33(11.3)$ & $58.81+27.81$ & within & 289 & 524.47 & .020 & .881 \\
\hline
\end{tabular}

$* \mathrm{p}=.05$

\section{Discussion}

In this study, the subjects experienced low levels of interpersonal conflict $($ Mean $=58.28$, S.D. $=22.86)$. This is inconsistent with previous studies' results in which nurses reported experiencing moderate [13-14] and high [15] levels of interpersonal conflict. The differences in the results could be due to the differences in the hospitals' cultures and work environments.

The low level of interpersonal conflict among nurses and the absence of a significant link between this score and the variables of age, marital status, education level, work time, appointment status and work experience could be explained by Chinese culture. Most Chinese people are collectivist with a strong emphasis on maintaining relationships. Collectivism leads them to be hesitant about engaging in aggressive interactions that may cause a 'loss of face' and damage the reputation of others [16]. A previous study showed the Chinese nurses usually adopt a harmonious approach, control their emotions, and avoid taking extreme positions in conflict [17]. In addition, that study was conducted in hospitals which adopted interdisciplinary rounds, interdisciplinary meetings, and clinical pathways to encourage nurse autonomy and collaboration with other disciplines. They had a clear division of labor: the doctors created a care plan for the patient, which the nurses implemented. The nurses provided care directly to patients, working within the guidelines of the care plan, but otherwise independently of the doctors [18].

Moreover, in recent years, the Dali hospital administrations have become more attentive towards teamwork. A number of improved initiatives have supported team-based working, thus promoting effective use of available resources in delivering high-quality patient care [19]. Team-building projects have been implemented in hospitals to improve trust, facilitate stable working relationships, clarify direction, encourage team bonding, and increase staff satisfaction about teamwork. Nurses who work in the multidisciplinary teams are more likely to pursue their team goals. They are also more likely to deliver high-quality care or services in greater quantities. Nurses who work in cohesive teams are more likely to have a sense of belonging and commitment to the team and have mutual trust and respect for each other [20].

Furthermore, the demographic profile of the nurses may explain the present study's results - specifically, the very high proportion of subjects that were female (99.31\%). Women are more likely to take others' interests into consideration, preferring more tactful strategies, whereas men prefer competitive, unyielding, and aggressive strategies [21]. This hypothesis is also supported by a previous study, the perception of intra-group and inter-group conflict were significantly higher for men than women [22].

The only variable which significantly affected interpersonal conflict scores in the current study was job status (Mean $=93.33$, S.D. $=43.10)$. In particular, the role of Associate Chief Nurse was significantly associated with higher interpersonal conflict scores. This may be explained by the nature of this position - an Associate Chief Nurse has greater responsibility for ensuring that nurses provide highquality care and services. It is reasonable to expect elevated levels of conflict with nurses in the performance of that endeavor. 


\section{Conclusion}

Overall, participants reported low levels of interpersonal conflict. Their age, marital status, education level, work time, appointment status, and work experience were nonsignificant variables associated with interpersonal conflict score. Job status was a significant variable associated with interpersonal conflict scores. These results may be useful for clinicians and health care providers and may support the development of strategies for reducing interpersonal conflict. Further study may conduct in other settings to compare the present study results.

\section{List of Abbreviations}

ANOVA $=$ Analysis of variance.

$\mathrm{M}=$ Mean. $\mathrm{SD}=$ Standard deviation.

$\mathrm{df}=$ degree of freedom

\section{Ethical Considerations}

Permission was obtained from a proper hospital authority. Written consent was taken from the study participants.

\section{References}

[1] Xu. Y, and R. Davidhizar, "Conflict management styles of Asian and Asian American nurses: Implications for the nurse manager" The Health Care Manager, vol. 23, no1, pp. 46-53, Jan-Mar 2004.

[2] B. L. Marquis, and C. J. Huston, Leadership roles and management functions in nursing: Theory and application. Philadelphia: Wolters Kluwer Health/Lippincott Williams \& Wilkins, 2011.

[3] C. K. De-Dreu, and L. R. Weingart, "Task versus relationship conflict, team performance, and team member satisfaction: A meta-analysis" Journal of Applied Psychology, vol. 88, no. 4, pp. 741-749, 2003.

[4] T. L. Simons, and R. S. Peterson, "Task conflict and relationship conflict in top management teams: The pivotal role of intragroup trust" Journal of Applied Psychology, vol. 85 , no. 1 , pp. $102-111,2000$.

[5] K. Jehn, and E. Mannix, "The dynamic nature of conflict: A longitudinal study of intra-group conflict and group performance" Academy of Management Journal, vol. 44, no. 2, pp. 238-25, April 2001.

[6] Jr. D. C. Baldwin, and S. R. Daugherty, "Interprofessional conflict and medical errors: results of a national multispecialty survey of hospital residents in the US" Journal of Interprofessional Care, vol. 22, no 6, pp. 573-586, December 2008 .

[7] P. J. Montana, and B. H. Charnov, Management, barron's educational series, hauppauge. New York, 2008.

[8] I. U. Haq, "The impact of interpersonal conflict on job outcomes: Mediating role of perception of organizational politics" Procedia-Social and Behavioral Sciences, vol. 25, pp. 287-310, 2011.

[9] J. M. Leon-Perez, F. J. Medina, A. Arenas, and L. Munduate, "The relationship between interpersonal conflict and workplace bullying' Journal of Managerial Psychology, vol. 30 , no. 3, pp. 250-263, 2015.

[10] C. A. Demsky, "Interpersonal conflict and employee wellbeing: The moderating role of recovery experiences" Dissertations and Theses, Portland State University. 2012.

[11] Nursing Report, Nursing department statistics of the First Affiliated Hospital of Dali University [in Chinese]. The First Affiliated Hospital of Dali University, 2016.

[12] T. Yamane, Statistic: An introductory analysis. Tokyo: Harper International, 1973.

[13] M. Z. A. Higazee, "Types and levels of conflicts experienced by nurses in the hospital settings" Health Science Journal, vol. 9, no 7. pp. 1-6, 2015.

[14] H. M. Elshimy, M. Abel El-Megid, and S. Mohamed, "Nursing conflict scale: Development of an instrument and testing its validity and reliability" The Scientific Journal of AlAzhar Medical Faculty (Girls), vol. 23, pp. 679-693, 2002.

[15] N. M. Zakari, N. I. Al Khamis, and H. Y. Hamadi, "Conflict and professionalism: Perceptions among nurses in Saudi Arabia”. International Nursing Review, vol. 57, no. 3, pp. 297304, September, 2010.

[16] T. Dean, H. Chun, and H. Haifa, "Social face and openmindedness: Constructive conflict in Asia" In Regional relevance and global impact (pp. 3-16). Asian Management Matters. London: Imperial College Press, 2000..

[17] Q. Zhan, P. Zhan, and L. N. Kong, "Research on the influence of emotional intelligence and mode of conflict processing on job burnout among junior nurses in tertiary hospitals [in Chinese]" Journal of Nursing Administration, vol. 13, no. 6, pp. 383-385, 2013.

[18] F. M. Feng, S. M. Xiao, and Y. Zhou, "Investigation and improved strategies of physician- nurse collaboration culture [in Chinese]". Chinese Journal of modern Nursing, vol. 20, no. 14, pp. 1713-1715, 2014.

[19] J. C. Zhang, and Y. Wu, "Research progress of physiciannurse collaboration and its influencing factors [in Chinese]". Chinese Journal of practical Nursing, vol. 31, no. 29, pp. 2259-2262, 2015.

[20] D. R. Deeter-Schmelz, and K. K. Norman, "Patient care teams and customer satisfaction: the role of team cohesion." Journal of Services Marketing, vol. 17, no. 7, pp. 666-684, 2003.

[21] P. E. Valentine, "Management of conflict: Do nurses/women handle it differently?" Journal of Advanced Nursing, vol. 22, no. 1, pp. 142-149, 1995.

[22] Tsuno et al., "Intragroup and intergroup conflict at work, psychological distress, and work engagement in a sample of employees in Japan" Industrial Health, vol. 47. no. 6, pp 640648, 2009. 